\title{
Frequency and predictors of thrombus inside the guiding catheter during interventional procedures: an optical coherence tomography study
}

\author{
Giancarla Scalone $\cdot$ Salvatore Brugaletta $\cdot$ Hector M. Garcia-Garcia • \\ Victoria Martin-Yuste - Yajaziel Azpeitia - Shuji Otsuki - Omar Gomez • \\ Xavier Freixa $\cdot$ Monica Masotti $\cdot$ Manel Sabaté
}

Received: 17 June 2014/ Accepted: 29 September 2014/Published online: 4 October 2014

(C) Springer Science+Business Media Dordrecht 2014

\begin{abstract}
Optical coherence tomography (OCT) is able to identify thrombus. We detect the frequency of thrombus inside the guiding catheter by OCT and its relationship with clinical and procedural factors. We screened 77 patients who underwent OCT pullbacks. Only patients with visible guiding catheter were finally included (35) and divided into thrombus (21) or no-thrombus group (14). Patients within thrombus group were mostly males (100 vs. $71 \%$, $p=0.05$ ), with acute coronary syndrome (76 vs. $36 \%$, $p=0.02$ ) and received more frequently percutaneous coronary intervention ( 86 vs. $43 \%, p=0.01$ ) as compared to other group. A second dose of heparin was more frequently administered in thrombus than in other group (86 vs. $50 \%$, $p=0.01)$. Time between first heparin administration and OCT pullback (41[28-57] vs. 20 min [10-32], $p=0.001$ ), time elapsed from second heparin administration and OCT pullback (29 [19-48] vs. $16 \min [12-22], p=0.002)$ and total procedural time (47 [36-69] vs. $31 \mathrm{~min}$ [26-39], $p=0.005$ ) were longer in thrombus compared to other group. At multivariate analysis, total procedural time and time between first heparin administration and OCT pullback were only predictors of intra-catheter thrombus (HR 0.6 [0.3-0.9], $p=0.03$ and HR 1.9 [1.1-3.2], $p=0.02$, respectively). Thrombus inside guiding catheter may be a frequent finding in long interventional procedure. Future studies are warranted to determine its clinical impact.
\end{abstract}

G. Scalone · S. Brugaletta ( $₫)$. V. Martin-Yuste - Y. Azpeitia ·

S. Otsuki - O. Gomez · X. Freixa · M. Masotti · M. Sabaté

Department of Cardiology, Thorax Institute, Hospital Clinic,

IDIBAPS, University of Barcelona, Barcelona, Spain

e-mail: sabrugaletta@gmail.com; sabrugal@clinic.ub.es

H. M. Garcia-Garcia

Thoraxcenter, Erasmus Medical Center, Rotterdam,

The Netherlands
Keywords Optical coherence tomography - Thrombus . Guiding catheter $\cdot$ Procedural time $\cdot$ Anticoagulation

\section{Introduction}

Over last years, optical coherence tomography (OCT) has contributed to clarify the pathophysiology of coronary atherosclerosis [1-6]. Specifically, it is able to identify plaque rupture, fibrous cap erosion and intracoronary thrombus in patients with acute myocardial infarction, with higher resolution as compared with other imaging techniques [6-9]. In particular, OCT represents the gold standard for intra-coronary thrombus detection, which appears as a mass attached to luminal surface or floating within the lumen or as a mass protruding in-between or over stent struts [4]. OCT is also capable to discriminate between 2 types of thrombus: red thrombus, characterized by high light attenuation and white thrombus, homogeneous, with low light attenuation [4].

Thrombus may be localized not only at intra-coronary level but also in the guiding catheter. It may be caused by a combination of the following: active and multiple instrumentation of the coronary artery during percutaneous coronary intervention (PCI), insufficient flushing of the guiding catheter; insufficient anticoagulation; instrumentation of the coronary artery by manual thrombectomy devices with fragmentation and loss of thrombus during retrieval of the aspiration catheter [10]. However, incidence and predictors of thrombus inside the guiding catheter has not been systematically investigated.

In our study, we sought to define the frequency of thrombus inside the guiding catheter by OCT and to investigate its relationship with clinical and procedural data. 


\section{Methods}

Study population

From September 2012 to September 2013, we screened all consecutive patients who underwent OCT pullback in our centre, selecting only those patients with visible guiding catheter on OCT pullback. Study population was therefore divided into two groups according to the presence of thrombus inside the guiding catheter or not (thrombus group and no thrombus group, respectively). Clinical and procedural data, as well as in-hospital clinical adverse events related to thrombus were recorded (acute myocardial infarction, cardiac death and intra-stent thrombosis).

Procedural data

All patients were taking dual antiplatelet therapy with aspirin and clopidogrel at least $24 \mathrm{~h}$ before the procedure.

According to the protocol of our Hospital, 5,000 IU of unfractionated heparin were administered at the beginning of coronary angiography and then, if PCI or OCT were decided, a second dose of heparin was immediately administered, according to patient's weight, in order to achieve the full dose of heparin (100 IU/kg). Instead, if PCI or OCT were already planned before the coronary angiography (e.g. OCT analysis of a stent previously implanted, staged PCI, etc.) patients received a full amount of heparin since the beginning of the interventional procedure. We did not perform activated coagulation time (ACT) test. GPIIb/IIIa Inhibitors and bivalirudin were not administered in any patient. Total procedural time was measured from arterial puncture up to the removal of the catheter from the coronary ostium. Thrombolysis in Myocardial Infarction (TIMI) flow grade was also evaluated.

The following procedural data were collected:

1. the amount of the first dose of heparin;

2. the amount of the second dose of heparin;

3. the overall dose of heparin;

4. the time lag between the first and second heparin administration ("FH-SH time");

5. the time lag between the first heparin administration and the OCT pullback ("FH-OCT time");

6. the time lag between the second heparin administration and the OCT pullback ("SH-OCT time");

7. total procedural time.

The type of guiding catheter employed for each OCT pullback was also reported.

All procedures performed in this study were in accordance with the ethical standards of the institutional and/or national research committee and with the 1964 Helsinki declaration and its later amendments or comparable ethical standards. An informed consent was obtained from all patients.

Angiographic and OCT image acquisition and analysis

The OCT acquisition was performed using a commercially available system for intra-coronary imaging (C7XR Fourier-Domain System; LightLab Imaging, Westford Massachusetts). Pullbacks were performed during continuous injection of contrast medium $(3 \mathrm{ml} / \mathrm{s}$, Iodixanol 370 , Visipaque, GE Health Care, Cork, Ireland) through the guide catheter with an injection pump. The automated pullback rate was $20 \mathrm{~mm} / \mathrm{s}$ and the frame rate was 100 frames. Intracoronary nitroglycerin bolus was always administered before OCT pullback.

All angiographic and OCT images were analysed by two independent observers blinded to clinical and procedural data. In particular, OCT images were analysed using an off-line review system (LightLab Imaging, Wesrford, MA, USA). In OCT pullback, the length of the imaged guiding catheter was measured and all frames with the guiding catheter visible were analysed. The number of total frames of guiding catheter and with visible thrombus were recorded.

Thrombus, defined as a mass attached to luminal surface or floating within the lumen [4] of the coronary or guiding catheter (Fig. 1a-c) was measured in every frame and reported as maximal, minimal and median thrombus area. Thrombus volume and the distance of thrombus from the ostium of guiding catheter were also reported. Finally, thrombus images were also analysed on order to characterize them as red, white or mixed thrombus [4].

Statistical analysis

Continuous variables are expressed as mean and standard deviation (SD) or median and interquartile range (IQR), as appropriate; categorical variables are reported as numbers and percentages. Continuous variables were compared between the two groups using independent $t$ test or MannWhitney U-test, as indicated, whereas proportions were compared by Fisher's exact. Linear regression model was used to investigate the role of clinical and procedural variables as predictors of thrombus inside the guiding catheter.

In particular, univariate analysis was performed and only variables retaining a statistical significant predictive value (i.e. acute coronary syndrome, percutaneous coronary intervention, number of patients who received a second heparin administration, FH-OCT time, SH-OCT time, total procedural time; two-tailed $p$ value $<0.05$ ) were included in a multivariable backward stepwise regression analysis. 
A

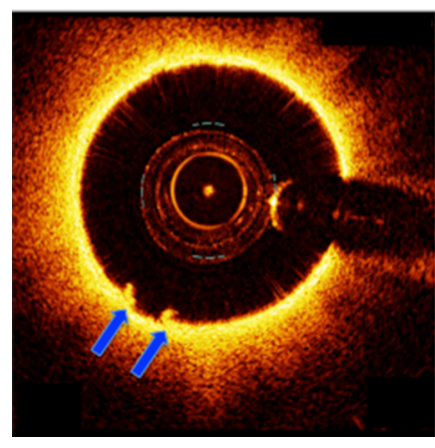

B

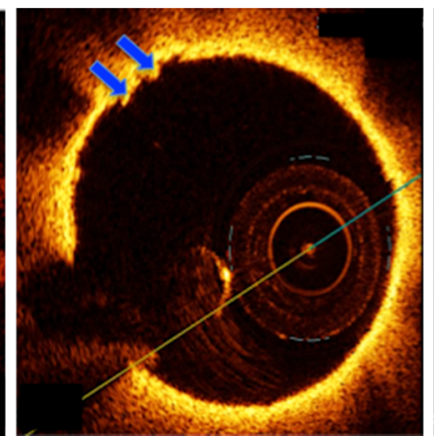

C

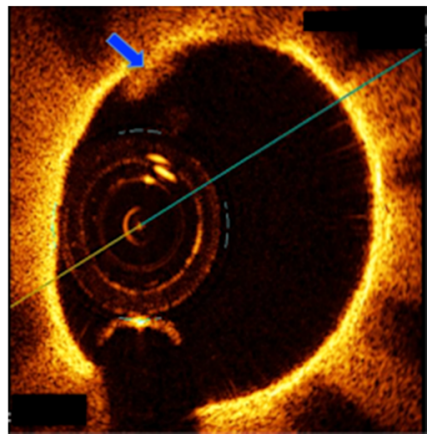

Fig. 1 Thrombotic images by OCT into catheter guide. According from the last consensus conference, thrombus was defined as a mass attached to luminal surface or floating within the lumen of the coronary or catheter guide (see blue arrows). The lengths of guiding catheter are $10.2 \mathrm{~mm} \mathrm{(a),} 13.2 \mathrm{~mm} \mathrm{(b)} \mathrm{and} 0.13 .1 \mathrm{~mm}$ (c), respectively

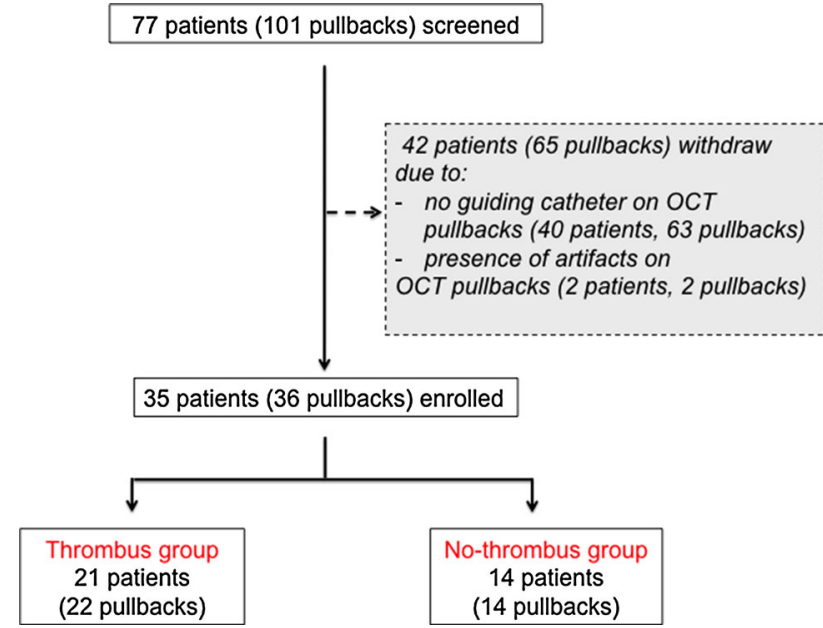

Fig. 2 Flow chart of the study. During the study period, 77 patients underwent OCT pullbacks (101 pullbacks overall). Forty patients (63 pullbacks) did not show the guiding catheter, whereas two of them (2 pullbacks) were excluded for presence of image artifacts on OCT pullback. Eventually, 35 patients (36 pullbacks) were enrolled in our study. Out of these, 21 patients (60\%) (22 pullbacks) had thrombus inside guiding catheter (thrombus group) and the remaining 14 (40\%) (14 pullbacks) did not (no-thrombus group)

The inter- and intra- observer agreement for OCT measurement was quantified by the Cohen's Kappa test for concordance [11].

Data were analyzed using SPSS for Windows version 20.0 software (SPSS Inc. Chicago, USA).

\section{Results}

Population study

During the study period, 77 patients underwent OCT analysis (101 pullbacks overall) (Fig. 2). Forty patients (63 pullbacks) did not have the guiding catheter visible on OCT pullback, whereas two patients (2 pullbacks) were
Table 1 Clinical characteristics of patients

\begin{tabular}{llll}
\hline & $\begin{array}{l}\text { Thrombus } \\
\text { group (21) }\end{array}$ & $\begin{array}{l}\text { No thrombus } \\
\text { group (14) }\end{array}$ & $p$ \\
\hline Age, years (mean \pm SD) & $67.5 \pm 10$ & $61.7 \pm 12$ & 0.13 \\
Gender, male, n (\%) & $21(100)$ & $10(71)$ & 0.05 \\
Weight, kg, (range) & $80(75-95)$ & $77(69-83)$ & 0.19 \\
Hypertension, n (\%) & $14(67)$ & $11(78)$ & 0.23 \\
Diabetes mellitus, n (\%) & $7(33)$ & $4(28)$ & 0.60 \\
Dyslipidemia, n (\%) & $12(57)$ & $6(43)$ & 0.42 \\
Smoking, n (\%) & $9(43)$ & $8(57)$ & 0.23 \\
Acute coronary syndrome, n (\%) & $16(76)$ & $5(36)$ & 0.02 \\
Chronic stable angina, n (\%) & $5(24)$ & $1(7)$ & 0.24 \\
Silent ischemia, n (\%) & $0(0)$ & $1(7)$ & 0.38 \\
Therapy & & & \\
Aspirin, n (\%) & $21(100)$ & $14(100)$ & 1.0 \\
Clopidogrel, n (\%) & $21(100)$ & $14(100)$ & 1.0 \\
Nitrates, n (\%) & $2(9)$ & $2(14)$ & 0.49 \\
Beta blockers, n (\%) & $13(62)$ & $10(71)$ & 0.29 \\
Calcium antagonist, n (\%) & $2(0)$ & $0(0)$ & 0.38 \\
ACE-inhibitor, n (\%) & $19(90)$ & $11(78)$ & 0.54 \\
Statins, n (\%) & $12(57)$ & $6(43)$ & 0.42 \\
\hline OCT optical cohere & & & \\
& & &
\end{tabular}

$O C T$ optical coherence tomography, ACE-inhibitors angiotensinconverting-enzyme inhibitor

* = at least $300 \mathrm{mg}$, after interventional procedure

excluded due to artifacts on OCT pullback. Eventually, 35 patients (36 pullbacks) were included in this study. Out of these, 21 patients $(60 \%)$ (22 pullbacks) had thrombus inside guiding catheter (thrombus group) and the remaining 14 (40\%) (14 pullbacks) did not (no-thrombus group). Of note, one patient of thrombus group received two OCT pullbacks: at the end of the PCI for acute coronary syndrome (ACS), and at follow-up assessment 1 month later. In both cases, OCT analysis showed thrombus inside the guiding catheter. 


\section{Clinical characteristics}

Baseline features of patients are shown in Table 1 .

There were no significant differences between groups in term of age and cardiovascular risk factors (smoking, hypertension, diabetes, dyslipidemia); however, patients within thrombus group were preferentially males (100 vs. $71 \%, p=0.05$ ) and admitted for ACS (76 vs. $36 \%$, $p=0.02$ ) as compared to no-thrombus group. Of note, in both groups, ACS consisted only of no ST segment elevation myocardial infarction (NSTEMI). No differences in terms of medical therapy were reported between the two groups. Fondaparinux was not administered in any patient. No in- hospital clinical adverse events were observed.

Procedural characteristics and OCT analysis

Procedural data are reported in the Table 2, whereas the data from OCT analysis are summarized by Table 3 .

All the procedures were performed by radial approach with 6 French guiding catheter. In the no-thrombus group, OCT was performed more frequently for follow-up assessment $(50 \%)$, compared to other group $(p=0.008)$.

Percutaneous coronary intervention was performed more frequently in thrombus compared to no-thrombus group (86 vs. $43 \%, p=0.016$ ). All patients presented TIMI 3 grade flow before and after the procedure. No angiographic images compatible with intra-coronary thrombus were detected in any case. In particular, no intra-coronary thrombus were detected in OCT pullbacks performed in thrombus group. Accordingly, thrombus-aspiration was not performed in any case.

Median length of imaged guiding catheter, analysed by OCT, was $11.1 \mathrm{~mm}$ [8.07-17.55 $\mathrm{mm}$ ]. The reproducibility of thrombus detection inter and intra-observer variabilities were 0.83 and $0.86 \kappa$, respectively. The overall number of frames with thrombus was 58 (mean value $2.5 \pm 1.5$ ), thus representing about the $4 \%$ of the total guiding catheter frames $(1,463)$. The mean overall thrombus area was $20 \mu^{2}$ [10-40 $\left.\mathrm{mm}^{2}\right]$, whereas thrombus median volume was $0.17 \mu \mathrm{m}^{3}\left[0.1-4.3 \mu \mathrm{m}^{3}\right]$.

The mean distance of the clots from the ostium of the guiding catheters was $7.25 \pm 5.6 \mathrm{~mm}$.

Moreover, within the thrombus group, $91 \%$ of thrombus were defined as white, while the remaining as red (Table 3). There are no differences in frequency of thrombus detected in the right compared to left catheters $(p=0.59)$ and among the various guiding catheters used $(p=0.97)$.

Total procedural time was longer in thrombus group compared to the other group ( $p=0.005$, Fig. 3a). There were no differences between groups in the amount of first, second and overall dose of heparin. However, thrombus
Table 2 Procedural characteristics

\begin{tabular}{|c|c|c|c|}
\hline & $\begin{array}{l}\text { Thrombus group } \\
\text { (n 21) } \\
\text { (pullbacks 22) }\end{array}$ & $\begin{array}{l}\text { No thrombus } \\
\text { group (n 14) } \\
\text { (pullbacks 14) }\end{array}$ & $p$ \\
\hline PCI, n (\%) & $19(86)$ & $6(43)$ & 0.01 \\
\hline Guiding catheter type & & & 0.97 \\
\hline EBU 3.5, n (\%) & $6(27)$ & $3(21)$ & \\
\hline JL $3.5, \mathrm{n}(\%)$ & $8(36)$ & $6(42)$ & \\
\hline $\mathrm{JR} 4, \mathrm{n}(\%)$ & $1(4)$ & $0(0)$ & \\
\hline AL $1, \mathrm{n}(\%)$ & $7(32)$ & $5(35)$ & \\
\hline $\begin{array}{l}\text { OCT performed for } \\
\text { follow-up } \\
\text { assessment, n (\%) }\end{array}$ & $2(9)$ & $7(50)$ & 0.008 \\
\hline $\begin{array}{l}\text { First dose of heparin } \\
\text { amount, IU } \\
(\text { mean } \pm \text { SD) }\end{array}$ & $5,700( \pm 1,572)$ & $6,107( \pm 1,903)$ & 0.17 \\
\hline $\begin{array}{l}\text { Second dose of } \\
\text { heparin amount, IU, } \\
(\text { mean } \pm \text { SD) }\end{array}$ & $3,300( \pm 1,917)$ & $2,800( \pm 636)$ & 0.81 \\
\hline $\begin{array}{l}\text { Total heparin } \\
\text { amount, IU, } \\
\text { (mean } \pm \mathrm{SD})\end{array}$ & $8,156( \pm 1,670)$ & $7,500( \pm 1,270)$ & 0.63 \\
\hline $\begin{array}{l}\text { Patients receiving a } \\
\text { second dose of } \\
\text { heparin, } \mathrm{n}(\%)\end{array}$ & $19(86)$ & $7(50)$ & 0.01 \\
\hline $\begin{array}{l}\text { Total procedural } \\
\text { time, min }[\mathrm{IQR}]\end{array}$ & 47 [36-69] & 31 [26-39] & 0.005 \\
\hline $\begin{array}{l}\text { FH-SH time, min } \\
{[\text { [IQT] }}\end{array}$ & 14 [12-16] & 13 [12-16] & 0.80 \\
\hline $\begin{array}{l}\text { FH-OCT time, min, } \\
\text { [IQR] }\end{array}$ & 41 [28-57] & 20 [10-32] & 0.001 \\
\hline $\begin{array}{l}\text { SH-OCT time, min, } \\
\text { [IQR] }\end{array}$ & 29 [19-48] & 16 [12-22] & 0.02 \\
\hline $\begin{array}{l}\text { Guide catheter } \\
\text { length, mm, [IQR] }\end{array}$ & $11.1[7.7-13.2]$ & $11.0[8.0-12.0]$ & 0.27 \\
\hline
\end{tabular}

$P C I$ percutaneous coronary intervention, $I Q R$ inter-quartile range, $S D$ standard deviation, $O C T$ optical coherence tomography

group patients received more often a second dose of heparin compared to the other group (86 vs. $50 \%, p=0.042$ ).

"FH-OCT time" ( $p=0.001$, Fig. 3b) and "SH-OCT time" ( $p=0.026$, Fig. 3c) were longer in the thrombus compared to no-thrombus group. Conversely, the "FH-SH time" was the same between groups (Fig. 3d).

At multivariate analysis, total procedural time and the "FH-OCT time" were the only predictors of thrombus inside the guiding catheter (HR 0.6 [0.37-0.96], $p=0.03$ and HR 1.9 [1.1-3.2], $p=0.02$, respectively).

\section{Discussion}

In our study we demonstrated that (1) thrombotic images are detected by OCT in more than half of guiding catheters, 
Table 3 Data from OCT analysis

\begin{tabular}{ll}
\hline OCT parameters & \\
\hline Total guiding catheter frames, $\mathrm{n}$ & 1,463 \\
Frames with thrombus, $\mathrm{n}$ & 58 \\
Frames with thrombus, $\mathrm{n}$ (mean $\pm \mathrm{SD})$ & $2.5 \pm 1.5$ \\
Thrombus characterization & \\
Red thrombus, $\mathrm{n}(\%)$ & $2(9 \%)$ \\
White thrombus, $\mathrm{n}(\%)$ & $20(91 \%)$ \\
Thrombus area values & \\
Median volume, $\mu \mathrm{m}^{3}$ [range] & $0.17[0.1-4.3]$ \\
Maximal area value, $\mu \mathrm{m}^{2}$, [range] & $40[20-60]$ \\
Minimal area value, $\mu \mathrm{m}^{2}$, [range] & $20[10-20]$ \\
Median area value, $\mu \mathrm{m}^{2}$, [range] & $20[10-40]$ \\
\hline
\end{tabular}

$O C T$ optical coherence tomography

preferentially in ACS patients submitted to PCI; (2) patients included in thrombus group received more frequently a second dose of heparin compared to those in nothrombus group, although no difference in overall dose of heparin was detected; (3) total procedural time, as well as the time lag between the administration of each dose of heparin and OCT pullback, were longer in thrombus than no-thrombus group.
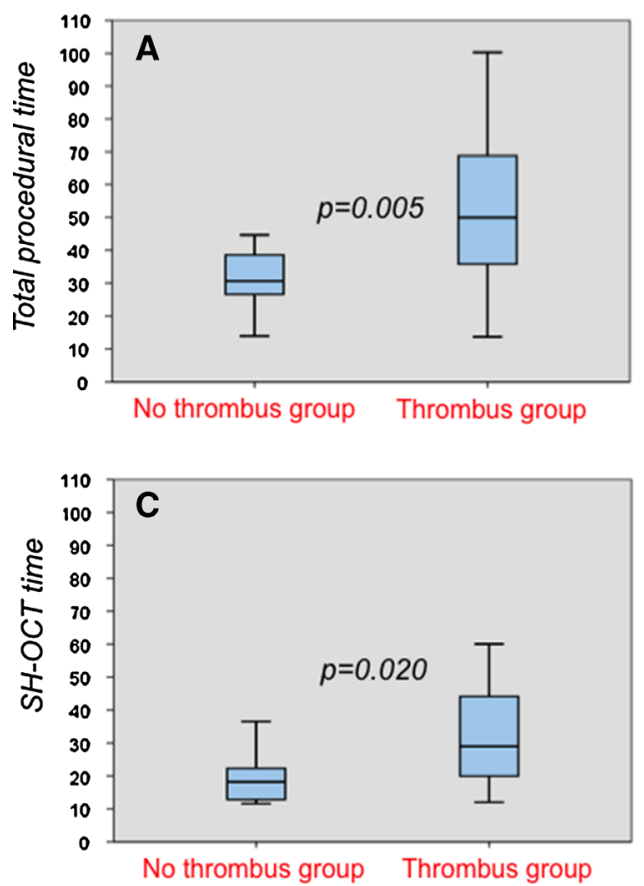

Fig. 3 a. Box plot showing the differences for the total procedural time, between the two groups, thrombotic group and no thrombotic group. Data are expressed as median [interquartile range]. b. Box plot showing the differences for the lag time between the first heparin administration and the OCT pullback ("FH-OCT time") in the two groups (thrombus group and no thrombus group). Data are expressed as median [interquartile range]. c. Box plot showing the differences
Over the last years, previous reports have been mostly focused on thrombotic images localized at intra-coronary levels [12-15], emphasizing its remarkable etiologic role in ACS with elevated thrombotic burden and pro thrombotic milieu $[16,17]$.

On the other hand, several studies have been focused on thrombotic images localized at intra-stent level, mostly by using imaging technique as OCT and Intravascular Ultrasound study [18-21].

Afterward, Yusuf et al. [22] reported that thrombus images might be detected also inside the guiding catheter. In particular they showed that, in a subgroup of ACS patients treated with fondaparinux who underwent PCI, there was an increased incidence of catheter thrombosisrelated events compared to those who received enoxaparin ( 0.9 vs. $0.4 \%, p<0.001)$. These findings suggest that, although fondaparinux is beneficial for the overall ACS patient population, there is a need for additional anticoagulation treatment during PCI. Accordingly, in the Switch III trial [23], an open-label prospective, randomized, multicenter pilot study aiming at comparing treatment with unfractionated heparin versus bivalirudin in NSTEMI patients initially treated with fondaparinux and undergoing PCI, no catheter thrombosis-related events were detected in both two arms.
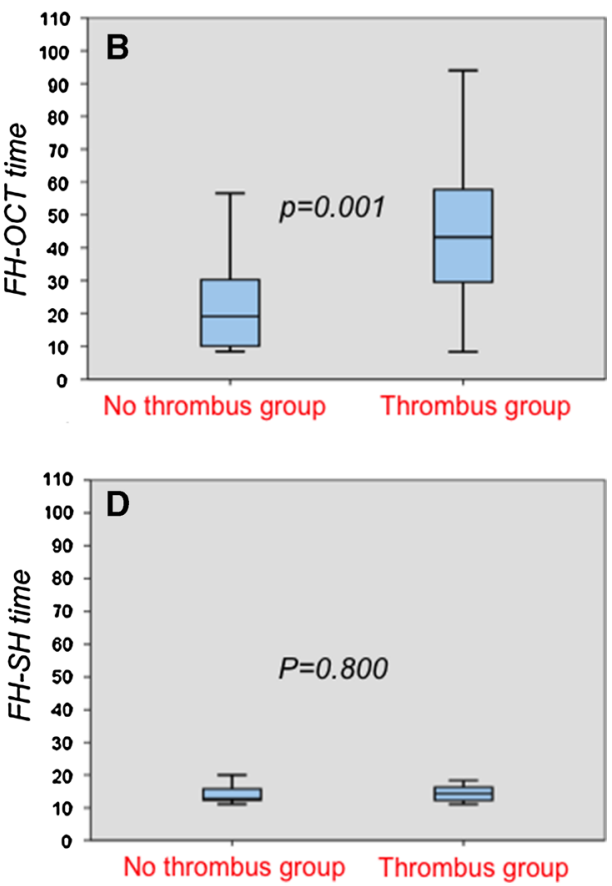

for the lag time between the second heparin administration and the OCT pullback ("SH-OCT time") in the two groups (thrombus group and no thrombus group). Data are expressed as median [interquartile range]. d. Box plot showing the differences for the lag time between the first heparin and the second heparin administration (" $\mathrm{FH}-\mathrm{SH}$ time") in the two groups (thrombus group and no thrombus group). Data are expressed as median [interquartile range] 
In our series, where heparin was the only anticoagulant used during coronary angiography, we identified thrombus images in $60 \%$ of patients with unintentional guiding catheter image acquisition by OCT.

The higher rate of catheter thrombosis in comparison with Yusuf' data (60 vs. $0.6 \%$ ) might be explained by the use, in our study, of the most sensitive imaging technique for thrombus detection.

Of note, we should also speculate that, just before OCT analysis, the interventional manouvers and also the intensity of flushing might have impact on these tiny thrombus formations inside the guiding catheter.

In detail, we showed that patients with thrombus image inside the guiding catheter performed OCT more frequently at the end of PCI, requiring two doses of heparin for the achievement of full amount. On the contrary, patients without thrombus inside guiding catheter, performed OCT more preferentially for follow-up assessment, thus receiving a full amount of heparin since the beginning of the interventional procedure. Of note, the same total amount of heparin was detected in both study groups. Moreover, a longer total procedural time, as well as the longer time between the administration of each dose of heparin and OCT pullback, were detected in patients with compared to those without intra-catheter thrombus image. Finally, the multivariate analysis showed that total procedural time and time between the administration of first dose of heparin and OCT pullback were independent predictors of intra-catheter thrombus. Taken together, our data highlight the crucial role of a long-lasting interventional procedure in intra-catheter thrombus formation.

Anticoagulant therapy is necessary in trans radial approach, to reduce the risks of radial artery occlusion after trans-radial catheterisation. In this context, Spaulding et al. showed that 5,000 IU of heparin are able to reduce the incidence of radial artery occlusion [24, 25]. According to these results, in the routine clinical practice of our Hospital, 5,000 IU of heparin are currently administered immediately after radial sheath introduction, at the beginning of the coronary angiography. Optimal anticoagulation is paramount during interventional procedures and ACT monitoring during long-lasting procedures is endorsed from the guidelines [26]. For PCI, the recommended target ACT is 250-300 s; unless abciximab is used, when a lower target ACT value (about $200 \mathrm{~s}$ ) is recommended [26]. ACT could play therefore a remarkable role both for the timing of administration and the choice of the proper dose of heparin.

In our study, thrombus formation could probably be associated with an insufficient anticoagulation. A possible explication of this phenomenon might be found in the considerable individual variability of heparin clearance from the bloodstream [27].
In particular, after parenteral injection, heparin is removed from the blood via two mechanisms, saturable and non-saturable. At dose of 5,000 IU, unfractionated heparin is removed mainly via the saturable mechanism. In our context, only after a complete saturation of its degradation systems, the increase of heparin concentration becomes linear [27]. The saturable clearance of this drug, accounts for the dose-dependent half-life of the heparin. For this reason, it is reasonable to choose a starting weight or body surface area based dose.

These data might explain the more frequent incidence of intra-catheter thrombus in patients receiving two fractioned sub-optimal doses of heparin compared to cases treated with a single weight based dose, administered from the beginning.

In this context, our data seem to suggest that, especially when a long-lasting interventional procedure is expected, it is reasonable to choose directly a starting weight based heparin dose in order to avoid an insufficient anticoagulation.

However, future larger dose-ranging studies, providing a systematical ACT monitoring during PCI, are required to clarify this point.

\section{Study limitations}

Our study presents several limitations: (1) although it represents the first contribution to detect the incidence of thrombus inside the guiding catheter by OCT, the small simple size requires to be expanded in future larger studies; (2) we did not provide a systematical evaluation of the heparin effect by ACT during the procedure; (3) new anticoagulants, as bivalirudin, were not used; (4) the small sample size does not allow to properly evaluate clinical events related to thrombus; (5) considering the retrospective nature of the study, we were not able to perform the histological analysis of the guiding catheter.

\section{Conclusion}

Thrombus inside guiding catheter represents a frequent finding in unintentional OCT image acquisition, especially in long-lasting interventional procedure. Future studies are warranted to determine its clinical impact.

Conflict of interest The authors declare that they have no conflict of interest.

Ethical standards The authors state that this study have been approved by the appropriate ethics committee and have therefore been performed in accordance with the ethical standards laid down in the 1964 Declaration of Helsinki and its later amendments.

Informed consent Informed consent was obtained from all individual participants included in the study 


\section{References}

1. Huang D, Swanson EA, Lin CP, Schuman JS, Stinson WG, Chang W, Hee MR, Flotte T, Gregory K, Puliafito CA (1991) Optical coherence tomography. Science 254:1178-1181

2. Bezerra HG, Costa MA, Guagliumi G, Rollins AM, Simon DI (2009) Intracoronary optical coherence tomography: a comprehensive review clinical and research applications. JACC Cardiovasc Interv 2:1035-1046

3. Kubo T, Akasaka T (2010) Optical coherence tomography imaging: current status and future perspectives : current and future developments in OCT. Cardiovasc Interv Ther 25:2-10

4. Tearney GJ, Regar E, Akasaka T, Adriaenssens T, Barlis P, Bezerra HG, Bouma B, Bruining N, Cho JM, Chowdhary S, Costa MA, de Silva R, Dijkstra J, Di Mario C, Dudek D, Falk E, Feldman MD, Fitzgerald P, Garcia-Garcia HM, Gonzalo N, Granada JF, Guagliumi G, Holm NR, Honda Y, Ikeno F, Kawasaki M, Kochman J, Koltowski L, Kubo T, Kume T, Kyono H, Lam CC, Lamouche G, Lee DP, Leon MB, Maehara A, Manfrini O, Mintz GS, Mizuno K, Morel MA, Nadkarni S, Okura H, Otake H, Pietrasik A, Prati F, Räber L, Radu MD, Rieber J, Riga M, Rollins A, Rosenberg M, Sirbu V, Serruys PW, Shimada K, Shinke T, Shite J, Siegel E, Sonoda S, Suter M, Takarada S, Tanaka A, Terashima M, Thim T, Uemura S, Ughi GJ, van Beusekom HM, van der Steen AF, van Es GA, van Soest G, Virmani R, Waxman S, Weissman NJ, Weisz G, International Working Group for Intravascular Optical Coherence Tomography (IWG-IVOCT) (2012) Consensus standards for acquisition, measurement, and reporting of intravascular optical coherence tomography studies. J Am Coll Cardiol 59:1058-1072

5. Jang IK, Tearney GJ, MacNeill B, Takano M, Moselewski F, Iftima N, Shishkov M, Houser S, Aretz HT, Halpern EF, Bouma BE (2005) In vivo characterization of coronary atherosclerotic plaque by use of optical coherence tomography. Circulation 111:1551-1555

6. Gonzalo N, Serruys PW, Barlis P, Ligthart J, Garcia-Garcia HM, Regar E (2010) Multi-modality intra-coronary plaque characterization: a pilot study. Int J Cardiol 138:32-39

7. Motoyama S, Sarai M, Harigaya H, Anno H, Inoue K, Hara T, Naruse H, Ishii J, Hishida H, Wong ND, Virmani R, Kondo T, Ozaki Y, Narula J (2009) Computed tomographic angiography characteristics of atherosclerotic plaques subsequently resulting in acute coronary syndrome. J Am Coll Cardiol 54:49-57

8. Kubo T, Imanishi T, Takarada S, Kuroi A, Ueno S, Yamano T, Tanimoto T, Matsuo Y, Masho T, Kitabata H, Tsuda K, Tomobuchi Y, Akasaka T (2007) Assessment of culprit lesion morphology in acute myocardial infarction: ability of optical coherence tomography compared with intravascular ultrasound and coronary angioscopy. J Am Coll Cardiol 50:933-939

9. Ozaki Y, Okumura M, Ismail TF, Motoyama S, Naruse H, Hattori K, Kawai H, Sarai M, Takagi Y, Ishii J, Anno H, Virmani R, Serruys PW, Narula J (2011) Coronary CT angiographic characteristics of culprit lesions in acute coronary syndromes not related to plaque rupture as defined by optical coherence tomography and angioscopy. Eur Heart J 32:2814-2823

10. Eeckhout E, Serruys PW, Wijns W, Vahanian A, van Sambeek M, De Palma R (eds) (2012) PCR-EAPCI textbook of percutaneous interventional cardiovascular medicine. Europa Publications, London

11. Cohen J (1960) A coefficient of agreement for nominal scales. Educ Psychol Meas 20:37-46

12. Vetrovec GW, Cowley MJ, Overton H, Richardson DW (1981) Intracoronary thrombus in syndromes of unstable myocardial ischemia. Am Heart J 102:1202-1208
13. Holmes DR Jr, Hartzler GO, Smith HC, Fuster V (1981) Coronary artery thrombosis in patients with unstable angina. Br Heart J 45:411-416

14. Ellis SG, Roubin GS, King SB, Douglas JS Jr, Weintraub WS, Thomas RG, Cox WR (1988) Angiographic and clinical predictors of acute closure after native vessel coronary angioplasty. Circulation 77:372-379

15. Singh M, Reeder GS, Ohman EM, Mathew V, Hillegass WB, Anderson RD, Gallup DS, Garratt KN, Holmes DR Jr (2001) Does the presence of thrombus seen on a coronary angiogram affect the outcome after percutaneous coronary angioplasty? An Angiographic Trials Pool data experience. J Am Coll Cardiol 38:624-630

16. Kirtane AJ, Sandhu P, Mehran R, McEntegart M, Cristea E, Brener SJ, Xu K, Fahy M, Généreux P, Wessler JD, Stone GW (2014) Association between intraprocedural thrombotic events and adverse outcomes after primary percutaneous coronary intervention for st-segment elevation myocardial infarction (a harmonizing outcomes with revascularization and stents in acute myocardial infarction [HORIZONS-AMI] substudy). Am J Cardiol 113:36-43

17. McEntegart MB, Kirtane AJ, Cristea E, Brener S, Mehran R, Fahy M, Moses JW, Stone GW (2012) Intraprocedural thrombotic events during percutaneous coronary intervention in patients with non-ST-segment elevation acute coronary syndromes are associated with adverse outcomes: analysis from the ACUITY (Acute Catheterization and Urgent Intervention Triage Strategy) trial. J Am Coll Cardiol 59:1745-1751

18. Otake H, Shite J, Ako J, Hinke T, Tanino Y, Ogasawara D, Sawada T, Miyoshi N, Kato H, Koo BK, Honda Y, Fitzgerald PJ, Hirata K (2012) Local determinants of thrombus formation following sirolimus-eluting stent implantation assessed by optical coherence tomography. JACC Cardiovasc Interv 2:459-466

19. Awata M, Kotani J, Uematsu M, Morozumi T, Watanabe T, Onishi T, Iida O, Sera F, Nanto S, Hori M, Nagata S (2007) Serial angioscopic evidence of incomplete neointimal coverage after sirolimus-eluting stent implantation: comparison with bare-metal stents. Circulation 116:910-916

20. Kotani J, Awata M, Nanto S, Uematsu M, Oshima F, Minamiguchi H, Mintz GS, Nagata S (2006) Incomplete neointimal coverage of sirolimus-eluting stents: angioscopic findings. J Am Coll Cardiol 47:2108-2111

21. Takano M, Ohba T, Inami S, Seimiya K, Sakai S, Mizuno K (2006) Angioscopic differences in neointimal coverage and in persistence of thrombus between sirolimus-eluting stents and bare metal stents after a 6-month implantation. Eur Heart J 27:2189-2195

22. Howe Fifth Organization to Assess Strategies in Acute Ischemic Syndromes Investigators, Yusuf S, Mehta SR, Chrolavicius S, Afzal R, Pogue J, Granger CB, Budaj A, Peters RJ, Bassand JP, Wallentin L, Joyner C, Fox KA (2006) Comparison of fondaparinux and enoxaparin in acute coronary syndromes. N Engl $\mathrm{J}$ Med 354:1464-1476

23. Waksman R, Bertrand O, Driesman M, Gruberg L, Rossi J, Mehta S, Swymelar S, Dvir D, Xue Z, Torguson R (2013) Bivalirudin versus unfractionated heparin during percutaneous coronary intervention in patients with non-ST-segment elevation acute coronary syndrome initially treated with fondaparinux: results from an international, multicenter, randomized pilot study (SWITCH III). J Interv Cardiol 26:107-113

24. Spaulding C, Lefevre T, Funck F, Thébault B, Chauveau M, Ben Hamda K, Chalet Y, Monségu H, Tsocanakis O, Py A, Guillard N, Weber S (1996) Left radial approach for coronary angiography: results of a prospective study. Cathet Cardiovasc Diagn 39:365-370 
25. Bernat I, Bertrand OF, Rokyta R, Kacer M, Pesek J, Koza J, Smid M, Bruhova H, Sterbakova G, Stepankova L, Costerousse O (2011) Efficacy and safety of transient ulnar artery compression to recanalize acute radial artery occlusion after transradial catheterization. Am J Cardiol 107:1698-1701

26. Cavusoglu E, Lakhani M, Marmur JD (2005) The activated clotting time (ACT) can be used to monitor enoxaparin and dalteparin after intravenous administration. J Invasive Cardiol 17:416-421

27. De Swart CA, Nijmeyer B, Roelofs JM, Sixma JJ (1982) Kinetics of intravenously administered heparin in normal humans. Blood 60:1251-1258 